Article

\title{
Summer Mass Balance and Surface Velocity Derived by Unmanned Aerial Vehicle on Debris-Covered Region of Baishui River Glacier No. 1, Yulong Snow Mountain
}

\author{
Yanjun Che ${ }^{1,2,3}$, Shijin Wang ${ }^{2, *}$, Shuhua $Y_{i}{ }^{4}$, Yanqiang Wei ${ }^{5}\left(\mathbb{D}\right.$ and Yancong Cai ${ }^{6}$ \\ 1 Department of Geography Science, Yichun University, Yichun 336000, China; cheyanjun@jxycu.edu.cn \\ 2 Yulong Snow Mountain Glacier and Environment Observation and Research Station/State Key Laboratory of \\ Cryospheric Sciences, Northwest Institute of Eco-Environment and Resources, Chinese Academy of Sciences, \\ Lanzhou 730000, China \\ 3 Nanchang Base of International Centre on Space Technologies for Natural and Cultural Heritage under the \\ Auspices of UNESCO/ Key Laboratory of Poyang Lake Wetland and Watershed Research (Jiangxi Normal \\ University), Ministry of Education, Nanchang 330000, China \\ 4 School of Geographic Science, Nantong University, Nantong 226000, China; yis@ntu.edu.cn \\ 5 Key Laboratory of Remote Sensing of Gansu Province, Northwest Institute of Eco-Environment and \\ Resources, Chinese Academy of Sciences, Lanzhou 730000, China; weiyq@lzb.ac.cn \\ 6 South China Sea Fisheries Research Institute, Chinese Academy of Fishery Sciences, Key Laboratory of \\ Open-Sea Fishery Development, Ministry of Agriculture and Rural Affairs, Guangzhou 510300, China; \\ caiyancong10@mails.ucas.ac.cn \\ * Correspondence: wangshijin@lzb.ac.cn
}

Received: 29 August 2020; Accepted: 4 October 2020; Published: 9 October 2020

\begin{abstract}
Glacier retreat is a common phenomenon in the Qinghai-Tibetan Plateau (QTP) with global warming during the past several decades, except for several mountains, such as the glaciers in the Karakoram and the western Kunlun Mountains. The dynamic nature of glaciers significantly influences the hydrologic, geologic, and ecological systems in the mountain regions. The sensitivity and dynamic response to climate change make glaciers excellent indicators of regional and global climate change, such as glacier melting and retreat with the rise of local air temperature. Long-term monitoring of glacier change is important to understand and assess past, current, and possible future climate environments. Some glacier surfaces are safe and accessible by foot, and are monitored using mass balance stakes and snow pits. Meanwhile, some glaciers with inaccessible termini may be surveyed using satellite remote images and Unmanned Aerial Vehicles (UAVs). Those inaccessible glaciers are generally covered by debris in the southeast QTP, which is hardly accessible due to the wide distribution of crevasses and cliffs. In this paper, we used the UAV to monitor the dynamic features of mass balance and velocity of the debris-covered region of Baishui River Glacier No. 1 (BRG1) on the Yulong Snow Mountain (YSM), Southeast QTP. We obtained the Orthomosaic and DEM with a high resolution of $0.10 \mathrm{~m}$ on 20 May and 22 September 2018, respectively. The comparison showed that the elevation of the debris-covered region of the BRG1 decreased by $6.58 \mathrm{~m} \pm 3.70 \mathrm{~m}$ on average, and the mean mass balance was $-5.92 \mathrm{~m}$ w.e. $\pm 3.33 \mathrm{~m}$ w.e. during the summer, correspondingly. The mean displacement of debris-covered glacier surface was $18.30 \mathrm{~m} \pm 6.27 \mathrm{~m}$, that is, the mean daily velocity was $0.14 \mathrm{~m} / \mathrm{d} \pm 0.05 \mathrm{~m} / \mathrm{d}$ during the summer. In addition, the UAV images not only revealed the different patterns of glacier melting and displacement but also captured the phenomena of mass loss due to ice avalanches at the glacier front and the development of large crevasses. This study provides a feasible method for understanding the dynamic features of global debris-covered glaciers which are inaccessible and unobservable by other means.
\end{abstract}


Keywords: unmanned aerial vehicle; mass balance; surface velocity; glacier

\section{Introduction}

Large amounts of glacier and snow resources are stored in the Qinghai-Tibetan Plateau (QTP), which supply important freshwater resources from glacier- and snow-melting feeds for more than 1.4 billion people of surrounding river basins, e.g., the Indus, Ganges, Brahmaputra, Yangtze, and Yellow rivers [1-5]. During the past decades, wide mass loss of glaciers has been observed. For example, the total mass balance of glaciers in High Mountain Asia (HMA) was $-19.0 \pm 2.5 \mathrm{Gt} / \mathrm{a}$ (i.e., $-0.19 \pm 0.03 \mathrm{~m}$ w.e./a) from 2000 to 2018 [6]. The melting is heterogeneous in space, for example, glacier mass balance ranged from $-0.30 \pm 0.12 \mathrm{~m}$ w.e./a to $-0.11 \pm 0.14 \mathrm{~m}$ w.e./a in the southeastern QTP, which was stronger than that in the northwestern QTP, with glacier mass balance ranging from $-0.11 \pm 0.13 \mathrm{~m}$ w.e./a to $0.02 \pm 0.10 \mathrm{~m}$ w.e./a [7]. In recent years, the geodetic methods of glacier mass balance and surface velocity have been widely applied using remotely sensed datasets, either spaceborne or airborne, as they provide a relatively easy and inexpensive method to obtain frequent data for large, possibly inaccessible areas [8].

The sensors used for estimates of elevation changes can be classified into two main categories: Active and passive [9]. Active elevation measurements mainly include airborne measurements equipped with Light Detection and Ranging (LiDAR), spaceborne measurements equipped with laser altimeters (e.g., ICESat's Geoscience Laser Altimeter System (GLAS) measurements, microwave ground-based measurements, and spaceborne techniques including Interferometric Synthetic Aperture Radar (InSAR) $[8,10,11]$. Passive elevation measurements use photogrammetry to generate elevation models, such as the stereo imageries from Corona and ASTER [12-14]. For the geodetic measurements of glacier surface velocity, manual or automated cross-correlation feature tracking is employed to optically sensed imagery, such as the images from Landsat Thematic Mapper (TM), Advanced Spaceborne Thermal Emission and Reflection Radiometer (ASTER), Satellite Pour 1'Observation de la Terre-5 (SPOT5), Envisat Advanced Synthetic Aperture Radar (ASAR), and Moderate Resolution Imaging Spectroradiometer (MODIS) [8,15-17]. As with the geodetic measurements of glacier mass balance and surface velocity, although the spatial extent of these products is covered in large areas, they have a relatively coarse horizontal resolution and relatively large vertical error. Shadows are difficult to detect with respect to these artifacts in the high sky. In addition, these products also considerably reduce the accuracy of the surface velocity or elevation change at specific locations [9].

Around $10 \%$ of the total glacier area in the HMA $[18,19]$ is covered by a debris layer, which generally controls the melting velocity of sub-ice. The proportion of glacier tongue surface covered by debris in the ablation zone has reached up to $\sim 40 \%$ in some regions, such as the Karakoram and Himalaya [20]. Consequently, future changes in water resources for heavily glaciered catchments partly depend on the long-term melting rates of debris-covered glaciers in the regions. The glaciers in the southeastern QTP are also called the "temperate or poly-thermal glacier" due to the relatively higher ice temperature, higher glacier velocity, stronger melting, accumulation, more debris-covered areas, etc. [21,22]. The local climate is affected by the water vapor from the Indian Ocean, Southeast Asian Monsoons, and Westerlies, as well as by a combination of local atmospheric circulation systems [23,24]. In addition, the glacier surface is covered with large crevasses and debris (Figure 1). Thus, it is difficult to access the glacier surface and the traditional glacier monitoring can hardly be conducted. For example, the limited mass-balance stakes are distributed on the middle zone of the Baishui River Glacier No. 1 (BRG1) of the Yulong Snow Mountain (YSM) in the southeastern QTP, while the most ablation zone is covered by debris and crevasses. Consequently, that the monitoring work was not conducted [22]. 


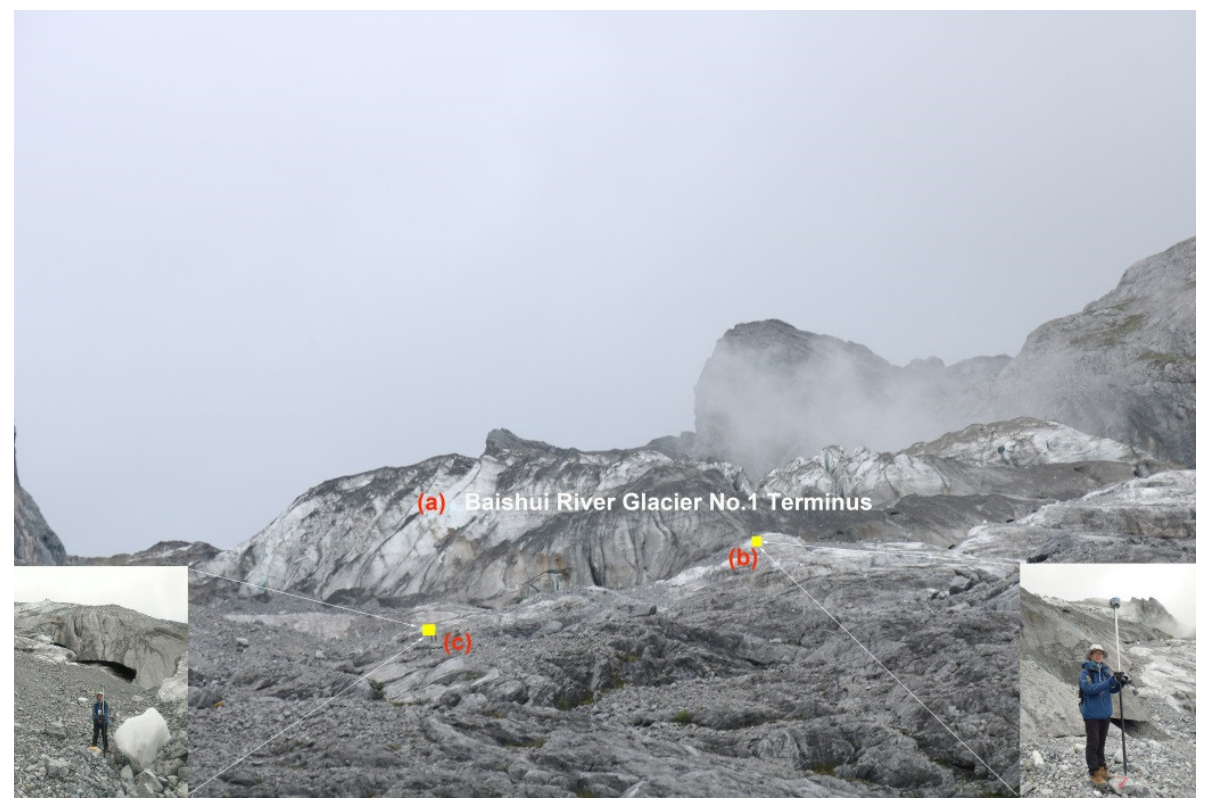

Figure 1. Photograph of glacier terminal. Its position was measured. In pictures, (a) denotes the glacier terminus of Baishui River Glacier No. 1; (b) denotes the glacier mass avalanching from the glacier front; and (c) denotes a ground control point at the end of the glacier.

In recent years, Unmanned Aerial Vehicles (UAVs) have been used to understand the dynamic features of glacier surface by repeated UAV photogrammetry, especially for debris-covered glaciers $[9,21,25]$. For example, the heterogeneous patterns of mass loss, surface velocity, and surface temperature on the debris-covered Lirung Glacier in Central Nepal were assessed by high-resolution images from an UAV, which revealed the important catalytic role for supraglacial lakes and ice cliffs $[9,20,26,27]$. In addition, an assessment of image network geometry and strength without Ground Control Points (GCPs) was also carried out, which suggests that the glacier images without GCPs have a good ability to describe the glacier surface features when providing a larger of feature points or matches points among the UAV photogrammetry images [25]. Though several studies on the UAV monitoring vegetation have been conducted to understand the ecosystem environment in the QTP [28,29], there has been no special study on the glacier melting and surface velocity in the region. The glaciers in the southeast QTP are significantly controlled by the Indian and southeast monsoons. These glaciers have stronger glacier ablation and accumulation, high velocity, large crevasses, and debris. However, the dynamic features and mass loss mechanisms of the debris-covered and crevasses-developed glaciers are still unclear. The features and mechanisms play an important role in understanding the relationship between glacier and climate.

During the past several decades, the in situ records of glacier melting and retreat have been conducted in the central glacier surface and terminus of BRG1 in the southeast QTP, respectively. The in situ data of debris-covered glacier are lacking, so we did not know much about the glacier surface features of mass loss and move. These surface features are very important to assess the glacier mass balance, understand the distribution of crevasses and cliffs, and reveal the relationship between glacier melting and local climate change. Herein, we carried out the two tests using an UAV to survey BRG1 on 20 May 2018 and 22 September 2018, respectively. Using UAV monitoring, the Orthomosaic and Digital Elevation Model (DEM) were obtained with high spatial resolutions in the debris-covered glacier during the summer seasons of 2018. The Orthomosaics and DEMs of a debris-covered glacier during the summer filled the data gap and were very important to assess the glacier mass loss and surface velocity in the area. 


\section{Study Area}

BRG1 is the largest glacier in the YSM, located in the southeast TP (Figure 2). The total glacier area disappeared by $64.02 \%$ in the YSM during the period 1957-2017 and decreased to $4.48 \mathrm{~km}^{2}$ in 2017 [22]. The elevation of the glaciers ranged from $5361 \mathrm{~m}$ a.s.l. to $4395 \mathrm{~m}$ a.s.l. The local climate is controlled by the Indian and southeast monsoons over the summer, while it was controlled by the south branch of the Westerly Belt during the winter and spring [24]. The precipitation is mainly concentrated in the warming seasons, i.e., June to September, which accounts for the $80 \% \sim 90 \%$ of the total of annual precipitation [30]. The average air temperature is $5.08^{\circ} \mathrm{C}$ in the monsoon season [31]. The glacier length decreased to $1.90 \mathrm{~km}$ from $2.65 \mathrm{~km}$ in 1957, and the glacier area decreased to $1.32 \mathrm{~km}^{2}$ in 2017 [22]. In addition, the area of debris-covered glacier accounts for $12-13 \%$ of the total area, and the debris is mainly concentrated on the glacier surface below $4600 \mathrm{~m}$ a.s.1., i.e., the region of repeated UAV surveyed in the study. Note that the debris-covered glacier region had previously been a field-data-free zone because of its inaccessibility and the coverage of crevasses and cliffs to observe in situ in the glacier tongue (Figure 1).



Figure 2. (a) Study area at the debris-covered tongue of Baishui River Glacier No. 1 in the Yulong Snow Mountain, located in the southeast Qinghai-Tibetan Plateau. (b) BRG1 is the largest glacier in the YSM, located in the southeast TP. The map also shows the range of UAV survey. In plot (c), the site d denotes the position of taken photo (d), and the site e denotes the position of taken photo (e).

\section{Data and Method}

\subsection{Unmanned Aerial Vehicle}

Considering the cost-effectiveness and aircraft stability, we used the Phantom 4 Pro (i.e., four-rotor drone) to survey the glacier surface. The UAV was produced by DJ-Innovations (DJI) and equipped with a CMOS image sensor with size of 1-inch and effective pixels of 20-megapixel, i.e., FC6310 [32]. The maximum flight time of the DJI Phantom 4 Pro was 30 minutes in the normal temperature environment with a low-elevation region, while it ranged from 15 minutes to 30 minutes in the alpine glacier region. The maximum relative height was $500 \mathrm{~m}$, while the maximum control distance was $\sim 7 \mathrm{~km}$. The drone was equipped with a Global Positioning System (GPS) and Global Navigation Satellite System (GLONASS), which provided accuracy position information. In addition, the controller and display equipment were required in order to make the normal drone flight. The drone hovered and took a photo in the air with a horizontal accuracy of $\pm 0.3 \mathrm{~m}$ and vertical accuracy of $\pm 0.1 \mathrm{~m}$ [32]. 
We found that the best time for UAV flight measurement was between 9 a.m. 12 a.m local time by analyzing many times of observations and experiments. Lower windspeed and less clouds occurred in the period, which benefitted the glacier survey using UAV flight. During the glacier survey, each flight time was set to 15-20 minutes in this region due to the lower air temperature.

\subsection{Flight Description}

Two surveys were conducted on the debris-covered area of the BRG1 on 20 May 2018 and 22 September 2018 (Figure 1c), approximately corresponding to the beginning and end points of the ablation season, respectively. In the first survey, three flights were operated between 9:45 a.m. and 11:00 a.m., while six flights were finished between 9:30 a.m. and 12:00 a.m in the second survey (Table 1). The surface elevation of the monitored glaciers ranged from approximately $4400 \mathrm{~m}$ a.s. 1 . to $4700 \mathrm{~m}$ a.s.l. The flight height of UAV measurement was set to $\sim 150 \mathrm{~m}$ above the glacier surface. However, the altitude of flight path had to be adjusted for each flight in order to keep a constant height above the glacier surface, especially in fights 3-6 (detailed information of the flights is shown in Figure 2 and Table 1). During the UAV flight measurement, the flight and photo collection were operated using the execution software of DJI GS Pro (https://www.dji.com/). For both campaigns, each image was acquired after focusing on the glacier surface, with a resolution of 5472 pixels $\times 3078$ pixels. To meet the condition of image mosaic in space, the image the overlap was set to $80 \%$ in both the lateral and longitudinal directions with respect to the UAV flight path.

Table 1. Overview of the Unmanned Aerial Vehicle (UAV) surveys performed in May and September 2018.

\begin{tabular}{ccccccc}
\hline Date & Time & Flight & $\begin{array}{c}\text { Glacier Area } \\
\text { Covered } \\
\mathbf{( k m}^{\mathbf{2}} \mathbf{n}\end{array}$ & $\begin{array}{c}\text { The } \\
\text { Number of } \\
\text { GCPs }\end{array}$ & $\begin{array}{c}\text { The } \\
\text { Number of } \\
\text { GCPs }\end{array}$ & $\begin{array}{c}\text { Photos } \\
\text { Taken }\end{array}$ \\
\hline 20 May 2018 & $9: 45-11: 00$ a.m. & Flights 1-3 & 0.08 & 10 & 6 & 67 \\
22 September 2018 & $9: 30-12: 00$ a.m. & Flights 1-6 & 0.16 & 11 & 7 & 106 \\
\hline
\end{tabular}

\subsection{Ground Control Points}

It was difficult to arrive at the debris-covered glacier surface in the glacier front, as travel paths were built on the south lateral moraine because the YSM was developed into a mature glacier resort. During the flight, 18 Ground Control Points (GCPs) were distributed on the south lateral moraine and bare rock at the end of the glacier. Approximately $60 \%$ of the GCPs was used for Orthomosaic and DEM generation, while the remaining $40 \%$ was used to validate the results of the generated models. That is, 6 of the 16 GCPs and 7 of the 18 GCPs were used as Ground Validation Points (GVPs) in the two surveys, respectively (Table 1). The treatment of these GCPs was the same in terms of the process of generating Orthomosaic and DEM images because these points were fixed during the study period. The output Orthomosaics and DEMs, with the spatial resolutions of $0.05 \mathrm{~m}$ and $0.09 \mathrm{~m}$, respectively, were resampled to $0.10 \mathrm{~m}$ in order to reduce the effects of any remaining motion blur as well as JPEG artifacts for further processing. In the procedure, the techniques of dealing with the georeferenced UAV photogrammetry were similar to those described by Immerzeel et al. [9], Kraaijenbrink et al. [26], and Rossini et al. [33].

In addition, the GCP and GVP coordinates were collected using differential global navigation satellite system (dGNSS) geodetic receivers (two CHCNAV X9 smart antennas and one CHCNAV controller HCE300). Then, the coordinates were corrected during post-processing [34]. Two identical smart antennas were used simultaneously: A base station and a rover. The base station was installed on the south lateral moraine of BRG1 and occupied this position for a cumulative time of over $16 \mathrm{~h}$. The rover was used to measure the inner corner points of each GCP and GVP, which were marked using red spray paint to ensure visibility. The dGNSS used during the surveys had a horizontal precision of $2.5 \mathrm{~mm}+0.5 \mathrm{ppm}$ and a vertical precision of $5 \mathrm{~mm}+0.5 \mathrm{ppm}$ according to CHCNAV X9 specification 
data. The coordinate of each point was measured by taking a measurement every second with at least four satellites in the field of view of the receiver according to the proposed protocol [35]. During the record processing, at first, a measurement point was called as a dynamic point due to the coordinate changing in real-time with more than four satellites. After, the point changed into a floating point after several minutes and recorded when it changed into a fixed point. It was recorded after several minutes (around more $6 \mathrm{~min}$ ) and an error threshold of $0.05 \mathrm{~m}$ was set during the measurement process. In other words, these precision errors of GCPs and GVPs were very small compared to the geodetic accuracy of the base station. Hence, they were negligible [9].

\subsection{Orthomosaic and DEM Generation}

Georeferenced photos collected during each UAV survey were assessed to obtain the vertical photogrammetry photos. The selected images must be cloudless and high-transmittance images, i.e., with sufficient quality and overlap from multiple positions and/or angles. These images were input and dealt with in the software Pix4Dmapper in order to generate the products of Orthomosaic and DEM. The data processing is shown in Figure 3. In addition, the process of images dealt with and output for the Orthomosaic and DEM was finished using Pix4Dmapper, which was fully described on the official homepage (https://www.pix4d.com/product/pix4dmapper-photogrammetry-software).

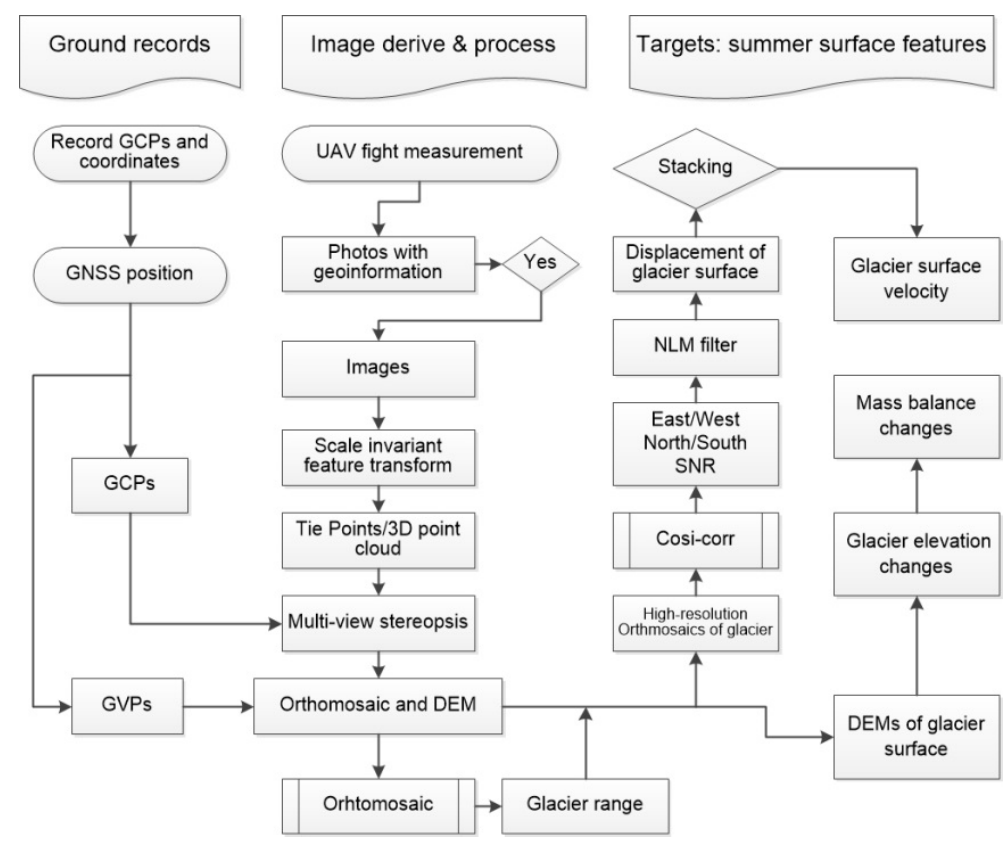

Figure 3. Workflow used for the assessment of glacier surface features.

When the georeferenced photos were chosen and input, the GCPs coordinates were also needed in the professional software. These images were then adjusted and aligned using an image feature recognition algorithm, which automatically detects and matches unique image feature characteristics (i.e., tie points) in the overlap region among these images [36]. The generation of Orthomosaic and DEM covered the flight region, which needed to be validated using the GVP coordinates. Subsequently, the Orthomosaic of the debris-covered glacier was manually interpreted and clipped from the generated Orthomosaic, including the non-glacier region. In addition, the DEM image of a debris-covered glacier was also generated. The data process was conducted, and the data processing progress is consistent with other studies $[9,25,26,33,37]$, especially the structure-from-motion applied to create Orthophtos and DEMs from the images collected during each UAV survey [38,39]. It is worth noting that the density of $900 \mathrm{~kg} / \mathrm{m}^{3}$ of glacier was used for converting changes in glacier surface elevation to changes in glacier mass balance. 


\subsection{COSI-Corr for Glacier Velocity}

COSI-Corr (Co-registration of Optically Sensed Images and Correlation) is a software tool developed to co-register pairs of optical remotely sensed images (aerials or satellites), which is used to look for seismic ground deformations, glacier flows, horizontal changes between multitemporal images, and so on $[40,41]$. The main tasks performed by COSI-Corr are precise orthorectification, image co-registration, and correlation, and it is specially designed to retrieve the sub-pixel displacements between optical images. This useful tool has been widely used and developed [42]. In recent years, the COSI-Corr has been widely used to compare the displacement of glacier surfaces using multitemporal images $[16,17,26,33,43]$, including aerial, Landsat, and MODIS images.

To assess the displacement of debris-covered glacier surveyed repeatedly, the two Orthomosaics of glacier surfaces were clipped to the same spatial range with a resolution of $0.10 \mathrm{~m}$. First, the post-event and pre-event images were input to the COSI-Corr tool in order to compare the displacement image. The calculating step in the $X$ and $Y$ directions was set as five in the correlation procession, respectively. The output image then included three bands with a resolution of $0.50 \mathrm{~m}$, respectively, i.e., the East/West band, North/South band, and SNR (Signal-to-Noise Ratio) band. Note that the value of SNR denotes the possibility of glacier displacement, ranging from 0 to 1 [44]. The closer the SNR was to 1, the larger the displacement of the glacier surface. On the contrary, the ground surface had almost displacement when the SNR was lower than the threshold value. As shown in Figure 4, the number of SNRs at different values was counted. Second, an SNR threshold of 0.956 was chosen to deal with some abnormal values using the function "Discard/Replace Image Values" in Cosi-Corr, such as the missing value $(\mathrm{NaN})$. Filtered bands of the East/West band and North/South band were also needed to perform the Non-Local Means Filter (NLM), as shown in the workflow process (Figure 3). Third, the NLM algorithm filtered data by stepping through the dataset one value at a time. At each datapoint, a small region of surrounding values (typically $5 \times 5$ or $7 \times 7$; here, $7 \times 7$, was adapted) was compared with other non-local values. This approach can remove the repetitive and redundant information in the image (e.g., additive white Gaussian noise) and has the effect of preserving true signals and features $[45,46]$. Finally, to obtain a relatively reliable result, the standard deviation was applied three times to constrain the boundaries of the glacier surface velocity (i.e., the "Stacking" process in Figure 3), of which the detailed technological process was shown in Figure 3.

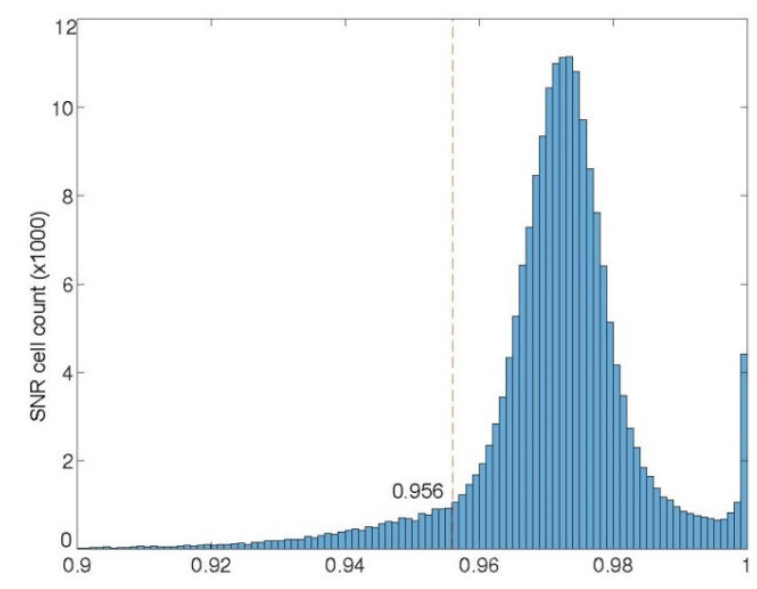

Figure 4. Histogram of Signal-to-Noise Ratio (SNR) with respect to the interested region.

\section{Results}

\subsection{Accuracy of DEMs and Orthomosaics}

The Phantom 4 Pro coordinates every image it takes using its GPS/GLONASS module, which has been carried out on th alpine glacier of Bernina Massif in the Raethian Alps and has presented high 
accuracy in DEMs and Orthophotos [33]. To deeply assess the accuracy of generating Orthomoasaics and DEMs, six GVPs and seven GVPs were used to check the imagery accuracy in May and September 2018, respectively. The errors of northing and easting were lower than $11 \mathrm{~cm}$ in both surveys, while the vertical error was lower than $12 \mathrm{~cm}$ (Table 2). The total Root Mean Square Error (RMSE) of GVPs in the $\mathrm{XY}$ directions (i.e., horizontal direction) was lower than $14 \mathrm{~cm}$ in both surveys, and the total RMSE was lower $18 \mathrm{~cm}$. Therefore, the generated DEMs and Ortomosaics showed good accuracy, which met the conditions of computing the images (e.g., glacier surface velocity and elevation changes). In addition, the credibility of results from comparing images in different times is described in the discussion section.

Table 2. Root mean square errors (RMSE) for the six Ground Validation Points (GVPs) and seven GVPs in the May and September 2018 surveys, respectively.

\begin{tabular}{cccccc}
\hline & $\begin{array}{c}\text { GVPs RMSE X } \\
(\mathbf{m})\end{array}$ & $\begin{array}{c}\text { GVPs RMSE Y } \\
(\mathbf{m})\end{array}$ & $\begin{array}{c}\text { GVPs RMSE Z } \\
(\mathbf{m})\end{array}$ & $\begin{array}{c}\text { GVPs XY RMSE } \\
(\mathbf{m})\end{array}$ & $\begin{array}{c}\text { GVPs Total RMSE } \\
(\mathbf{m})\end{array}$ \\
\hline 20 May 2018 & 0.10 & 0.08 & 0.12 & 0.13 & 0.18 \\
22 September 2018 & 0.09 & 0.08 & 0.11 & 0.12 & 0.16 \\
\hline
\end{tabular}

\subsection{Orthomosaic and Digital Elevation Model}

Based on the UAV images of drone flights on 20 May and 22 September 2018, we derived detailed Orthomosaics and DEMs for the debris-covered glacier surface with a resolution of $0.10 \mathrm{~m}$, respectively (Figure 5). The first monitoring was implemented on 20 May 2018, and the debris-covered area of $0.08 \mathrm{~km}^{2}$ in front of the glacier was monitored (Figure $5 \mathrm{~b}$ ). The UAV flew three sorties due to the lack of special experience, including flight 1, flight 2, and flight 3 (Figure 5a). The first monitored DEM of glacier surfaces ranged from $4573 \mathrm{~m}$ a.s.1. to $4426 \mathrm{~m}$ a.s.l. (Figure 5c), while the Orthomosaic presented a lot of detailed topographic information on the glacier surface. Compared with the first monitor, six flights were operated and derived more UAV images on 22 September 2018. The monitored glacier surface area reached $0.16 \mathrm{~km}^{2}$, and DEM of the corresponding area ranged from $4438 \mathrm{~m}$ a.s.1. to $4708 \mathrm{~m}$ a.s.l. (Figure 5d,e).
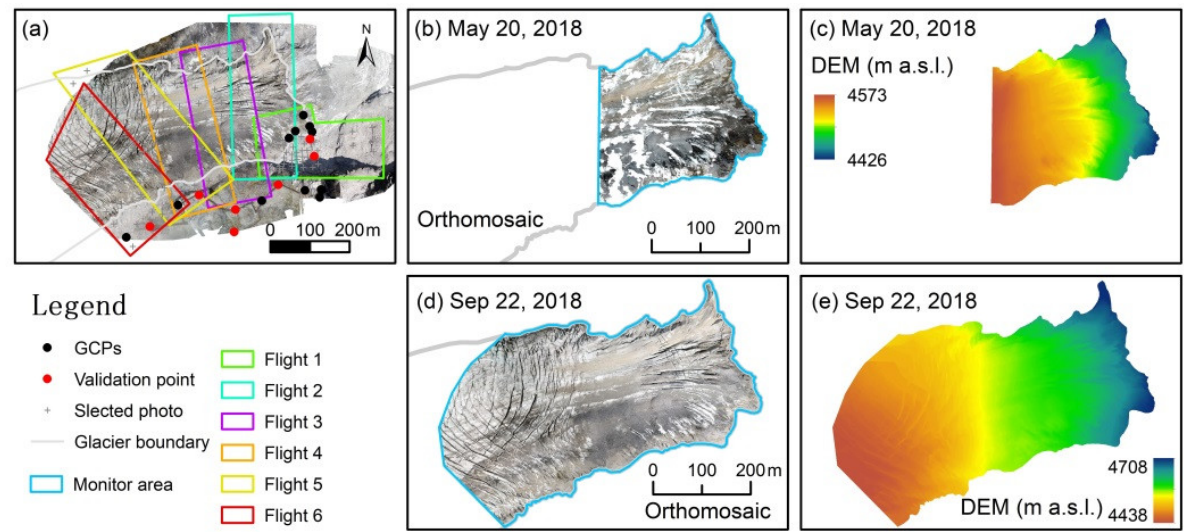

Figure 5. Orthomosaics and digital elevation models derived from UAV monitoring on 20 May and 22 September 2018, respectively. In plots, (a) denotes the information of UAV flights and Ground Control Points and Ground Validation Points; $(\mathbf{b}, \mathbf{c})$ denote the Orthomosaic and DEM images of UAV monitoring on 20 May 2018, respectively; (d,e) denote the Orthomosaic and DEM images of UAV monitoring on 22 September 2018, respectively.

\subsection{Mass Balance of Debris-Covered Glacier}

The first monitored glacier front (Figure 5b) was covered by thicker debris. In order to accurately assess the elevation change of the glacier surface, the same regions in the twice-monitored glacier surface were compared (Figure 6a). During the period from 20 May to 22 September, the elevation of the 
glacier front surface dropped, on average, by $6.58 \mathrm{~m} \pm 3.70 \mathrm{~m}$ (arithmetic mean \pm standard deviation). The maximum decrease in glacier surface elevation was $32.51 \mathrm{~m}$, while the maximum elevation increase was $9.68 \mathrm{~m}$. We also found that some stronger areas of glacier surface elevation decrease happened at the crevasse edge and in ice cliff regions. The elevation change was used to calculate the mass balance of the glacier front using an ice density of $900 \mathrm{~kg} / \mathrm{m}^{3}$. The results showed that the mean mass balance of the glacier front was $-5.92 \mathrm{~m}$ w.e. $\pm 3.33 \mathrm{~m}$ w.e. (arithmetic mean \pm standard deviation) (Figure 6b), in which the maximum value of mass balance was $8.77 \mathrm{~m}$ w.e., while the minimum value was $-29.26 \mathrm{~m}$ w.e.
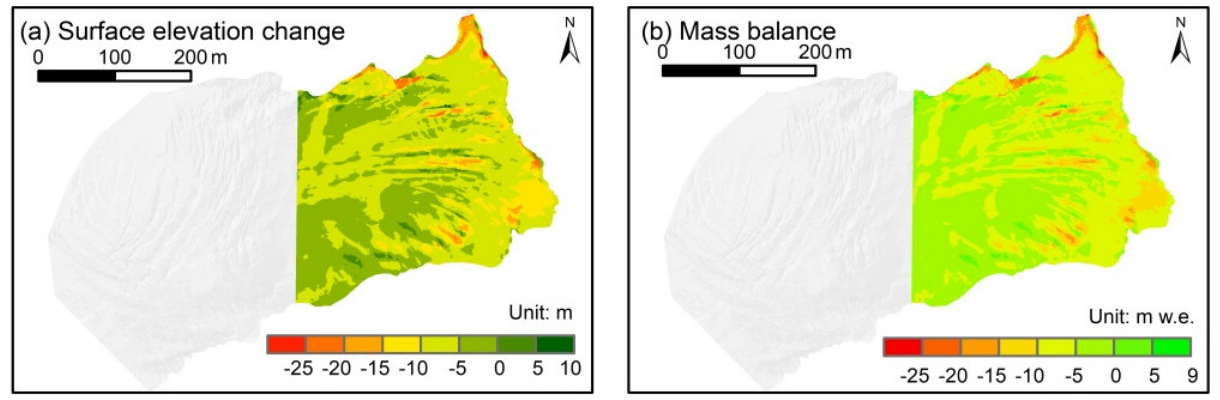

Figure 6. Elevation change of glacier surface monitored by UAV from 20 May to 22 September 2018. In plots, (a) denotes the total change of glacier surface elevation, and (b) denotes the mass balance of glacier surface.

\subsection{Summer Surface Velocity}

During the summer, i.e., from 20 May to 22 September 2018, we produced two high-resolution Orthomosaics of the overlap region with the area of $0.08 \mathrm{~km}^{2}$ in the glacier front. The displacement of the glacier surface in the same region was computed by the Cosi-corr tool in ENVI. As shown in Figure 7a, we found that the glacier mainly moved from west to east, with a mean glacier surface displacement of $18.30 \mathrm{~m} \pm 6.27 \mathrm{~m}$ (arithmetic mean \pm standard deviation) during the study period. The maximum displacement of the debris-covered surface was $37.04 \mathrm{~m}$, while the minimum displacement was $0.81 \mathrm{~m}$. The glacier displacement in the overlap region showed a significant difference in space. We found that the distribution of the relatively small or large displacements was dispersed in space. Notably, the relatively stronger displacements did not occur in the terminus of the glacier front. For this point, we inferred that the discrepancy in surface displacement was mainly controlled by the local ice surface slope, ice thickness, ice density, and temperature [47].
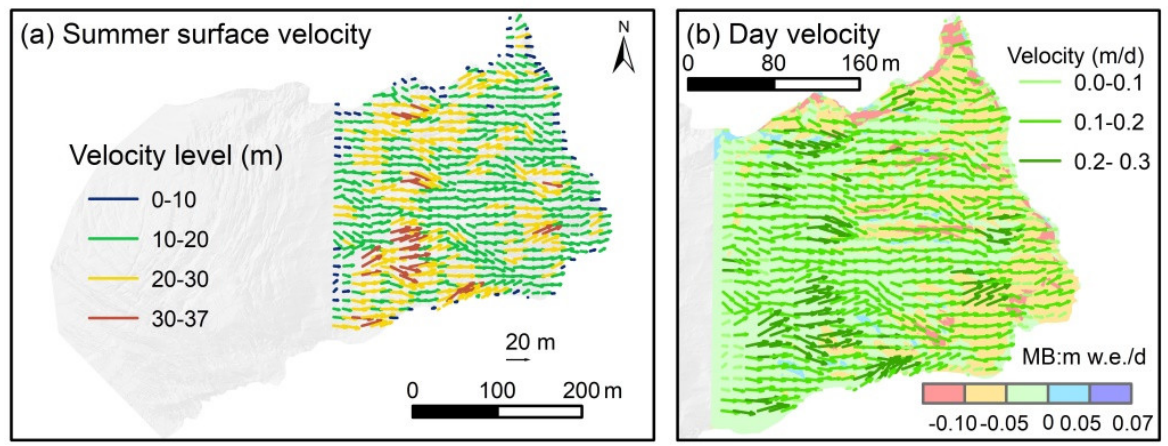

Figure 7. Glacier surface displacement of the debris-covered glacier derived from the two surveys in the glacier front. In plots, (a) denotes the surface displacement distance of the debris-covered glacier from 20 May to 22 September in 2018; (b) denotes the surface velocity and mass balance of debris-covered glacier per day during the summer. 
Here, 125 days between the two UAV monitoring tests in the summer were used to compute the glacier surface velocity per day. The mean daily velocity of the glacier debris-covered surface was $0.14 \mathrm{~m} / \mathrm{d} \pm 0.05 \mathrm{~m} / \mathrm{d}$ (arithmetic mean \pm standard deviation) during the summer. The maximum velocity of the glacier surface was $0.30 \mathrm{~m} / \mathrm{d}$, while the minimum velocity was $0.01 \mathrm{~m} / \mathrm{d}$. In addition, the melt velocity of the glacier debris-covered surface was also assessed (Figure $7 \mathrm{~b}$ ). The mass balance per day ranged from $-0.23 \mathrm{~m}$ w.e./d to $0.07 \mathrm{~m}$ w.e./d, with the mean mass balance of $-0.05 \mathrm{~m}$ w.e. $/ \mathrm{d} \pm 0.03 \mathrm{~m}$ w.e./d (arithmetic mean \pm standard deviation).

\section{Discussion}

\subsection{Accuracy of DEMs and Orthomosaics}

Using GCPs can improve the accuracy of generating DEM and Orthomosaics from aerial mapping surveys. The ground control points can be measured by some methods, i.e., traditional surveying methods, LiDAR, an existing map, and even Google Earth [48-50]. Many researchers think that adding more ground control points takes more time but creates more accurate drone maps, but does it? To test how many GCPs are really required for accurate results, the Nevada Department of Transportation (DOT) set out a series of tests. A DJI Phantom 4 Pro drone and Pix4D mapper software were used during the experiment and a covered area of $\sim 0.14 \mathrm{~km}^{2}$ (i.e., 34 acres) was measured. The results showed that 11-13 GCPs would likely be the most efficient number for geometry. The Northing and Easting RMSEs were $1.52 \mathrm{~cm}$ (i.e., 0.05 feet) when the number of GCPs ranged from 18 to 4 GCPs. The vertical RMSE was about $1.52 \mathrm{~cm}$ (i.e., 0.05 feet) from 18 to 14 GCPs and consistently around $3.05 \mathrm{~cm}$ (i.e., 0.1 feet) from 10 to 4 GCPs. In addition, reducing the number of GCPs by four to a total of seven located on the outside of the study region led to a maximum vertical difference of $13.41 \mathrm{~cm}$ (i.e., $0.44 \mathrm{feet}$ ) and vertical RMSE of $7.31 \mathrm{~cm}$ (i.e., 0.24 feet). A more detailed description of this assessment process was presented in the official document [32]. Herein, the number of GCPs in our study met the condition of generating the high-resolution images. The total RMSE of GCPs was lower than $20 \mathrm{~cm}$, which was slightly higher than DOT experiment because the topography of the glacierized region was more complicated.

\subsection{Changes in the Elevation and Mass Balance}

It was widely accepted that the elevation change of the glacier surface is translated into the change of glacier mass balance to better understand the glacier melting. Here, we justly discussed the mass balance with respect to understanding glacier surface change. The annual mass balance of the BRG1 ranged from -1.94 to $2.26 \mathrm{~m}$ w.e. during the period 1952-2017 according to the glaciology measurement [22,51]. Based on the observation at $4700 \mathrm{~m}$ a.s.l. from 2008 to 2013, the mass balance of the BRG1 ranged from $-3.64 \mathrm{~m}$ w.e. to $3.10 \mathrm{~m}$ w.e. from June to September, especially the mass balances of $-3.53 \mathrm{~m}$ w.e. and $-3.64 \mathrm{~m}$ w.e. in the melt seasons of 2008-2009 and 2009-2010, respectively [51]. The mean mass balance in situ at $4700 \mathrm{~m}$ w.e. was around $-3.22 \mathrm{~m}$ w.e. in the melting seasons from 2008 to 2013 , and the maximum and minimum mass loss were $-3.64 \mathrm{~m}$ w.e. and $-2.63 \mathrm{~m}$ w.e., respectively. In addition, the seasonal fluctuation of the glacier mass balance gradient, which changed with elevation, was lower than that of the annual change. For example, the mean mass balance gradient from July to September 2013 was $0.72 \mathrm{~m}$ w.e./(100m) from $4600 \mathrm{~m}$ a.s.l. to $4900 \mathrm{~m}$ a.s.l, which was significantly lower than $1.45 \mathrm{~m}$ w.e./(100m) from 2012 to 2013. In this paper, the mean glacier surface elevation of our repeatedly monitored glacier area was around $4551 \mathrm{~m}$ a.s.l. (Figure $5 \mathrm{c}$ ). We deduced that the mean mass balance of the melting season ranged from $-4.71 \mathrm{~m}$ w.e. to $-3.70 \mathrm{~m}$ w.e. on the debris-covered glacier using the mass balance and mass balance gradient of the melting season during the period 2008-2013. Correspondingly, the mean mass balance in the melting season was around $-4.29 \mathrm{~m}$ w.e. during that timespan.

In addition, the debris-covered glaciers in the Himalaya, being similar to glacier in YSM in terms of glacier surface feature, may have a spatially averaged rate of surface height change that is similar 
to those observed on bare-ice glaciers, despite the protected effects of thick debris. Those surfaces of debris-covered glaciers usually develop many ice cliffs. However, the mechanisms controlling the formation and survival of cliffs remain largely unknown [52]. An assessment of understanding the distribution and characteristics of these surface features on the debris-covered glacier was lunched in the Lantang Glacier located in the Himalaya, using UAV to obtain high-resolution Orthomosaics and elevation models [37]. The results indicated that the cliffs play an important role in the mass loss of debris-covered glaciers, as they melt comparatively faster than others. The mass loss from ice cliffs has hardly been considered using the traditional glacier mass balance method. In other words, the mean mass balance of $-4.29 \mathrm{~m}$ w.e., calculated during the period of the melt seasons at the front of BRG1 in YSM from 2008 to 2013, was lower than that of the actual melt. That is, the actual mass balance of melt season should have been lower than $-4.29 \mathrm{~m}$ w.e. Therefore, the computed result of mass balance (-5.92 m w.e. $\pm 3.33 \mathrm{~m}$ w.e.) from UAV surveying in terms of the melt season was credible and close to the actual situation. After all, the air temperature was warming from 2013 to 2018 [22].

\subsection{Glacier Surface Velocity}

To understand the glacier surface velocity, a campaign monitoring the displacement of 16 mass balance stakes distributed the regions from $4800 \mathrm{~m}$ a.s.1. to $4600 \mathrm{~m}$ a.s.1. of the BRG1 was carried out during the period of July-October 2016 [53]. The Trimble GeoXT of manual dGPS was used in the campaign and its accuracy was within $0.10 \mathrm{~m}$. The results showed that the monthly glacier surface velocity was at $2.28 \mathrm{~m} /$ month in terms of the entire glacier. The mean daily velocity of 16 stakes was $0.11 \mathrm{~m} /$ day during the melt season, while the mean daily velocity of the debris-covered glacier was $0.14 \mathrm{~m} /$ day $\pm 0.05 \mathrm{~m} /$ day using UAV repeat photogrammetry. Similar studies also found that the surface velocity at the end of the glacier was faster than that of the glacier surface with higher elevation [54-56]. For example, the observation in the Yanzigou glacier in the Gongga Mountains, located in the northeast region of the YSM, showed that the change of glacier surface velocity on the ablation area was more significant than that at the end of the glacier [56]. Besides, we also found that the glacier surface with the highest velocity was not the same as the glacier region with the most loss of glacier mass balance (Figure 7b). Overall, the surface velocity of the debris-covered glacier computed using the high-resolution images from UAV photogrammetry showed high accuracy and was very close to the actual velocity.

\subsection{Advantages and Disadvantages of the UAV Monitoring}

In the past decades, optical Very High Resolution (VHR) and Synthetic Aperture Radar (SAR) imagery have been rapidly produced and have represented effective tools in the glacier monitoring [57]. Although these spaceborne platforms had short revisiting times (i.e., ranging from one day to a few days), the time and spatial resolutions of satellite imagery still did not match the means of UAVs. Compared with spaceborne platforms, the advantages of UAV monitoring are significant. For example, the UAV photogrammetry was applied for to survey, monitor, and obtain characteristics of glacier surface elevation, surface velocity, supra-glacial lakes, crevasses, and unstable cliffs [57,58]. The mass loss from ice avalanches in glacier fronts had been ignored, and the phenomenon was not revealed until the application of UAV [37]. Meanwhile, the disadvantages of UAV monitoring also cannot be ignored [57]. For example, a fixed-wing platform needs a proper takeoff and landing sites, which is sometimes difficult to locate in rugged mountainous terrain. The length of UAV flight has been relatively short. The longest flight duration of a multirotor drone cannot currently exceed one hour. In addition, power consumption is faster in the glacier region than that in the plain region due to the low-temperature environment. The area of UAV monitoring is also limited. To make sure the high-resolution and high-overlap rate for images, the UAV has to fly at a special mid- and low-altitude over the glacier surface. Thus, future development of UAV monitoring should focus on these problems. Increased battery capacity is important to address short aircraft endurance. However, it is more 
important to focus on the bridge function of UAV monitoring between the ground observation and satellite technology of glacier monitoring.

\section{Conclusions}

UAVs are an important tool with respect to the study glacier melt and dynamic in ablation zones. Here, two UAV experiments were conducted to measure the glacier topography for the debris-covered glacier of the BRG1 on the YSM. Using UAV flight photogrammetry, we obtained the high-resolution Orthomosaic and DEM images with a resolution of $0.10 \mathrm{~m}$. The images provided detailed information of the unobservable glacier surface. By comparing the different time images, we computed the dynamic features of debris-covered glacier on the ablation zones in the summer. During the period from 20 May to 22 September in 2018, the elevation changes of the debris-covered glacier ranged from $-32.51 \mathrm{~m}$ to $9.68 \mathrm{~m}$, while the mean mass balance decreased by $6.58 \mathrm{~m} \pm 3.70 \mathrm{~m}$. Correspondingly, the mean mass balance of the glacier front was $-5.92 \mathrm{~m}$ w.e. $\pm 3.33 \mathrm{~m}$ w.e. In addition, during the summer, we found that debris-covered glacier surface displacement ranged from $37.04 \mathrm{~m}$ to $0.81 \mathrm{~m}$, with a mean displacement of $18.30 \mathrm{~m} \pm 6.27 \mathrm{~m}$. The mean daily velocity was $0.14 \mathrm{~m} / \mathrm{d} \pm 0.05 \mathrm{~m} / \mathrm{d}$. The results provide the new insights to understand glacier dynamic features for the debris-covered glacier, which reveal the accuracy mass balance and glacier displacement and also provide validation for glacier modeling and remote-sensing assessments.

Author Contributions: Conceptualization, S.W. and Y.C. (Yanjun Che); methodology, S.Y.; software and data curation, Y.W.; investigation, Y.C. (Yanjun Che) and Y.C. (Yancong Cai); validation, Y.C. (Yancong Cai) and Y.C. (Yanjun Che). All authors contributed to the writing of the paper. All authors have read and agreed to the published version of the manuscript.

Funding: This research was supported by Jiangxi Provincial Natural Science Foundation (No.20202BAB213013), Strategic priority research program of the Chinese Academy of Sciences (No. XDA19070503), State Key Laboratory of Cryospheric Science (SKLCS-ZZ-2020), the projection of Environmental Monitoring and Protection in Longhu Mountains of World Natural Heritage Site from Nanchang Base of International Centre on Space Technologies for Natural and Cultural Heritage under the Auspices of UNESCO (HIST-NB), and also supported by the Opening Fund of Key Laboratory of Poyang Lake Wetland and Watershed Research (Jiangxi Normal University), Ministry of Education (PK2020002).

Acknowledgments: We sincerely thank the Yulong Snow Mountain Glacier and Environment Observation Research Station, China Academic Science for providing the observation records for Baishui River Glacier No.1. We also thank Li Teng from Beijing Normal University for providing the technological help in the dealing with images.

Conflicts of Interest: The authors declare no conflict of interest.

\section{References}

1. Immerzeel, W.W.; van Beek, L.P.H.; Bierkens, M.F.P. Climate Change Will Affect the Asian Water Towers. Sciences 2010, 328, 1382-1385. [CrossRef]

2. Immerzeel, W.W.; Lutz, A.F.; Andrade, M.; Bahl, A.; Biemans, H.; Bolch, T.; Hyde, S.; Brumby, S.; Davies, B.J.; Elmore, A.C.; et al. Importance and Vulnerability of the World's Water Towers. Nature 2020, 577, 364-369. [CrossRef] [PubMed]

3. Yao, T.; Wu, G.; Xu, B.; Wang, W.; Gao, J.; An, B. Asian Water Tower Change and Its Impacts. Bull. Chin. Acad. Sci. 2019, 34, 1203-1209.

4. Farinotti, D. Cryospheric Science: Asia's Glacier Changes. Nat. Geosci. 2017, 10, 621-622. [CrossRef]

5. Usami, N.; Muhuri, A.; Bhattacharya, A.; Hirose, A. Proposal of Wet Snowmapping with Focus on Incident Angle Influential to Depolarization of Surface Scattering. In Proceedings of the 2016 IEEE International Geoscience and Remote Sensing Symposium (IGARSS), Beijing, China, 10-15 July 2016.

6. Shean, D.E.; Bhushan, S.; Montesano, P.; Rounce, D.R.; Arendt, A.; Osmanoglu, B. A Systematic, Regional Assessment of High Mountain Asia Glacier Mass Balance. Front. Earth Sci. 2020, 7, 363. [CrossRef]

7. Zhou, Y.; Li, Z.; Li, J.; Zhao, R.; Ding, X. Glacier Mass Balance in the Qinghai-Tibet Plateau and Its Surroundings from the Mid-1970s to 2000 Based on Hexagon Kh-9 and Srtm Dems. Remote Sens. Environ. 2018, 210, 96-112. [CrossRef] 
8. Paul, F.; Bolch, T.; Kääb, A.; Nagler, T.; Nuth, C.; Scharrer, K.; Shepherd, A.; Strozzi, T.; Ticconi, F.; Bhambri, R.; et al. The Glaciers Climate Change Initiative: Methods for Creating Glacier Area, Elevation Change and Velocity Products. Remote Sens. Environ. 2015, 162, 408-426. [CrossRef]

9. Immerzeel, W.W.; Kraaijenbrink, P.D.A.; Shea, J.M.; Shrestha, A.B.; Pellicciotti, F.; Bierkens, M.F.P.; de Jong, S.M. High-Resolution Monitoring of Himalayan Glacier Dynamics Using Unmanned Aerial Vehicles. Remote Sens. Environ. 2014, 150, 93-103. [CrossRef]

10. Arnold, N.S.; Rees, W.G.; Devereux, B.J.; Amable, G.S. Evaluating the Potential of High-Resolution Airborne Lidar Data in Glaciology. Int. J. Remote Sens. 2006, 27, 1233-1251. [CrossRef]

11. Robson, B.A.; Nuth, C.; Dahl, S.O.; Hölbling, D.; Strozzi, T.; Nielsen, P.R. Automated Classification of Debris-Covered Glaciers Combining Optical, Sar and Topographic Data in an Object-Based Environment. Remote Sens. Environ. 2015, 170, 372-387. [CrossRef]

12. Kaab, A.; Berthier, E.; Nuth, C.; Gardelle, J.; Arnaud, Y. Contrasting Patterns of Early Twenty-First-Century Glacier Mass Change in the Himalayas. Nature 2012, 488, 495-498. [CrossRef] [PubMed]

13. Brun, F.; Berthier, E.; Wagnon, P.; Kaab, A.; Treichler, D. A Spatially Resolved Estimate of High Mountain Asia Glacier Mass Balances from 2000 to 2016. Nat. Geosci. 2017, 10, 668-673. [CrossRef] [PubMed]

14. Maurer, J.M.; Schaefer, J.M.; Rupper, S.; Corley, A. Acceleration of Ice Loss across the Himalayas over the Past 40 Years. Sci. Adv. 2019, 5, eaav7266. [CrossRef] [PubMed]

15. Rignot, E.; Kanagaratnam, P. Changes in the Velocity Structure of the Greenland Ice Sheet. Sciences 2006, 311, 986-990. [CrossRef] [PubMed]

16. Li, T.; Liu, Y.; Li, T.; Hui, F.; Chen, Z.; Cheng, X. Antarctic Surface Ice Velocity Retrieval from Modis-Based Mosaic of Antarctica (Moa). Remote Sens. 2018, 10, 1045. [CrossRef]

17. Fahnestock, M.; Scambos, T.; Moon, T.; Gardner, A.; Haran, T.; Klinger, M. Rapid Large-Area Mapping of Ice Flow Using Landsat 8. Remote Sens. Environ. 2016, 185, 84-94. [CrossRef]

18. Scherler, D.; Bookhagen, B.; Strecker, M.R. Spatially Variable Response of Himalayan Glaciers to Climate Change Affected by Debris Cover. Nat. Geosci. 2011, 4, 156-159. [CrossRef]

19. Gardelle, J.; Berthier, E.; Arnaud, Y.; Kaab, A. Region-Wide Glacier Mass Balances over the Pamir-Karakoram-Himalaya during 1999-2011. Cryosphere 2013, 7, 1885-1886. [CrossRef]

20. Kraaijenbrink, P.D.A.; Bierkens, M.F.P.; Lutz, A.F.; Immerzeel, W.W. Impact of a Global Temperature Rise of 1.5 Degrees Celsius on Asia's Glaciers. Nature 2017, 549, 257-260. [CrossRef]

21. Kraaijenbrink, P.D.A.; Shea, J.M.; Litt, M.; Steiner, J.F.; Treichler, D.; Koch, I.; Immerzeel, W.W. Mapping Surface Temperatures on a Debris-Covered Glacier with an Unmanned Aerial Vehicle. Front. Earth Sci. 2018, 6, 64. [CrossRef]

22. Wang, S.; Che, Y.; Pang, H.; Du, J.; Zhang, Z. Accelerated Changes of Glaciers in the Yulong Snow Mountain, Southeast Qinghai-Tibetan Plateau. Reg Environ. Chang. 2020, 20, 38. [CrossRef]

23. Neckel, N.; Kropáček, J.; Bolch, T.; Hochschild, V. Glacier Mass Changes on the Tibetan Plateau 2003-2009 Derived from Icesat Laser Altimetry Measurements. Environ. Res. Lett. 2014, 9, 014009. [CrossRef]

24. Yao, T.; Thompson, L.; Yang, W.; Yu, W.; Gao, Y.; Guo, X.; Yang, X.; Duan, K.; Zhao, H.; Xu, B.; et al. Different Glacier Status with Atmospheric Circulations in Tibetan Plateau and Surroundings. Nat. Clim. Chang. 2012, 2, 663-667. [CrossRef]

25. Li, T.; Zhang, B.; Cheng, X.; Westoby, M.J.; Li, Z.; Ma, C.; Hui, F.; Shokr, M.; Liu, Y.; Chen, Z.; et al. Resolving Fine-Scale Surface Features on Polar Sea Ice: A First Assessment of Uas Photogrammetry without Ground Control. Remote Sens. 2019, 11, 784. [CrossRef]

26. Kraaijenbrink, P.; Meijer, S.W.; Shea, J.M.; Pellicciotti, F.; De Jong, S.M.; Immerzeel, W.W. Seasonal Surface Velocities of a Himalayan Glacier Derived by Automated Correlation of Unmanned Aerial Vehicle Imagery. Ann. Glaciol. 2016, 57, 103-113. [CrossRef]

27. Tonkin, T.N.; Midgley, N.G.; Cook, S.J.; Graham, D.J. Ice-Cored Moraine Degradation Mapped and Quantified Using an Unmanned Aerial Vehicle: A Case Study from a Polythermal Glacier in Svalbard. Geomorphology 2016, 258, 1-10. [CrossRef]

28. Qin, Y.; Yi, S.; Ding, Y.; Zhang, W.; Qin, Y.; Chen, J.; Wang, Z. Effect of Plateau Pika Disturbance and Patchiness on Ecosystem Carbon Emissions in Alpine Meadow in the Northeastern Part of Qinghai-Tibetan Plateau. Biogeosciences 2019, 16, 1097-1109. [CrossRef]

29. Sun, Y.; Hou, F.; Angerer, J.P.; Yi, S. Effects of Topography and Land-Use Patterns on the Spatial Heterogeneity of Terracette Landscapes in the Loess Plateau, China. Ecol. Indic. 2020, 109, 105839. [CrossRef] 
30. He, Y.; Theakstone, W.H.; Zhonglin, Z.; Dian, Z.; Tandong, Y.; Tuo, C.; Yongping, S.; Hongxi, P. Asynchronous Holocene Climatic Change across China. Quat. Res. 2004, 61, 52-63. [CrossRef]

31. Niu, H.; Kang, S.; Shi, X.; Paudyal, R.; He, Y.; Li, G.; Wang, S.; Pu, T.; Shi, X. In-Situ Measurements of Light-Absorbing Impurities in Snow of Glacier on Mt. Yulong and Implications for Radiative Forcing Estimates. Sci. Total Environ. 2017, 581-582, 848-856. [CrossRef]

32. DJI-Innovation. Phantom 4 pro/pro+release notes. Available online: https://www.dji.com/phantom-4-pro (accessed on 1 May 2018).

33. Rossini, M.; Di Mauro, B.; Garzonio, R.; Baccolo, G.; Cavallini, G.; Mattavelli, M.; De Amicis, M.; Colombo, R. Rapid Melting Dynamics of an Alpine Glacier with Repeated Uav Photogrammetry. Geomorphology 2018, 304, 159-172. [CrossRef]

34. Bernhard, H.-W.; Herbert, L.; Elmar, W. Gnss—Global Navigation Satellite Systems; Springer: Verlag Wien, Austria, 2008.

35. Hegarty, C.J.; Chatre, E. Evolution of the Global Navigation Satellitesystem (Gnss). Proc IEEE 2008, 96, 1902-1917. [CrossRef]

36. Lowe, D.G. Distinctive Image Features from Scale-Invariant Keypoints. Int. J. Comput. Vis. 2004, 60, 91-110. [CrossRef]

37. Kraaijenbrink, P.D.A.; Shea, J.M.; Pellicciotti, F.; Jong, S.M.D.; Immerzeel, W.W. Object-Based Analysis of Unmanned Aerial Vehicle Imagery to Map and Characterise Surface Features on a Debris-Covered Glacier. Remote Sens. Environ. 2016, 186, 581-595. [CrossRef]

38. Lucieer, A.; Jong, S.M.D.; Turner, D. Mapping Landslide Displacements Using Structure from Motion (SFM) and Image Correlation of Multi-Temporal UAV Photography. Prog. Phys. Geogr. 2014, 38, 97-116. [CrossRef]

39. Westoby, M.J.; Brasington, J.; Glasser, N.F.; Hambrey, M.J.; Reynolds, J.M. 'Structure-from-Motion' Photogrammetry: A Low-Cost, Effective Tool for Geoscience Applications. Geomorphology 2012, 179, 300-314. [CrossRef]

40. Leprince, S.; Barbot, S.; Ayoub, F.; Avouac, J. Automatic and Precise Orthorectification, Coregistration, and Subpixel Correlation of Satellite Images, Application to Ground Deformation Measurements. IEEE Trans. Geosci. Remote Sens. 2007, 45, 1529-1558. [CrossRef]

41. Ayoub, F.; Leprince, S.; Avouac, J.-P. Co-Registration and Correlation of Aerial Photographs for Ground Deformation Measurements. Int. J. Photogramm. Remote Sens. 2009, 64, 551-560. [CrossRef]

42. Van Puymbroeck, N.; Michel, R.; Binet, R.; Avouac, J.P.; Taboury, J. Measuring Earthquakes from Optical Satellite Images. Appl. Opt. 2000, 39, 3486-3494. [CrossRef]

43. Baird, T.; Bristow, C.S.; Vermeesch, P. Measuring Sand Dune Migration Rates with Cosi-Corr and Landsat: Opportunities and Challenges. Remote Sens. 2019, 11, 2423. [CrossRef]

44. Muhuri, A.; Bhattacharya, A.; Natsuaki, R.; Hirose, A. Glacier Surface Velocity Estimation Using Stokes Vector Correlation. In Proceedings of the 2015 IEEE 5th Asia-Pacific Conference on Synthetic Aperture Radar (APSAR), Singapore, 1-4 September 2015.

45. Buades, A.; Coll, B.; Morel, J. The Staircasing Effect in Neighborhood Filters and Its Solution. IEEE Trans. Image Process. 2006, 15, 1499-1505. [CrossRef] [PubMed]

46. Goossens, B.; Luong, H.; Pizurica, A.; Philips, W. An Improved Non-Local Denoising Algorithm. In Proceeding of the Local and Non-Local Approximation in Image Processing, International Workshop, Lausanne, Switzerland, 25-29 August 2008; pp. 143-156.

47. Jiskoot, H. Glacier Surging. In Encyclopedia of Snow, Ice and Glaciers; Singh, V.P., Singh, P., Haritashya, U.K., Eds.; Springer: Dordrecht, The Netherlands, 2011; pp. 415-428.

48. Benker, S.C.; Langford, R.P.; Pavlis, T.L. Positional Accuracy of the Google Earth Terrain Model Derived from Stratigraphic Unconformities in the Big Bend Region, Texas, USA. Geocarto Int. 2011, 26, 291-303.

49. Goudarzi, M.A.; Landry, R., Jr. Assessing Horizontal Positional Accuracy of Google Earth Imagery in the City of Montreal, Canada. Geod. Cartogr. 2017, 43, 56-65. [CrossRef]

50. Salinas-Castillo, W.E.; Paredes-Hernández, C.U. Horizontal and Vertical Accuracy of Google Earth ${ }^{\circledR}$ : Comment on 'Positional Accuracy of the Google Earth Terrain Model Derived from Stratigraphic Unconformities in the Big Bend Region, Texas, USA' by s.C. Benker, r.P. Langford and t.L. Pavlis. Geocarto Int. 2014, 29, 625-627. [CrossRef]

51. Du, J.; He, Y.; Li, S.; Wang, S.; Niu, H. Mass Balance of a Typical Monsoonal Temperate Glacier in Hengduan Mountains Region. Acta Geogr. Sin. 2015, 70, 1415-1422. 
52. Ragettli, S.; Bolch, T.; Pellicciotti, F. Heterogeneous Glacier Thinning Patterns over the Last 40 Years in Langtang Himal, Nepal. Cryosphere 2016, 10, 2075-2097. [CrossRef]

53. Yan, X.; He, Y.; Zhang, S.; Niu, H.; Zhu, G.; Wang, S.; Pu, T.; Shi, X.; Shi, X.; Qi, C. Analysis of Surface Flow Velocity on the Baishui Glacier No.1 during Ablation in the Yulong Mountain. J. Glaciol. Geocryol. 2017, 39, 1212-1220.

54. Cao, M.; Li, Z.; Li, H. Features of the Surface Flow Velocity on the Qingbingtan Glacier No.72, Tianshan Mountains. J. Glaciol. Geocryol. 2011, 33, 21-29.

55. Li, J. Glaciers in Hengduan Mountains; Science Press: Beijing, China, 1996.

56. Zhang, G. The Study of Glacier Changes in the Gongga Mountains; Lanzhou University: Lanzhou, China, 2012.

57. Casagli, N.; Frodella, W.; Morelli, S.; Tofani, V.; Ciampalini, A.; Intrieri, E.; Raspini, F.; Rossi, G.; Tanteri, L.; Lu, P. Spaceborne, UAV and Ground-Based Remote Sensing Techniques for Landslide Mapping, Monitoring and Early Warning. Geoenviron. Disasters 2017, 4, 9. [CrossRef]

58. Bhardwaj, A.; Sam, L.; Akanksha; Martín-Torres, F.; Kumar, R. UAVs as Remote Sensing Platform in Glaciology: Present Applications and Future Prospects. Remote Sens. Environ. 2016, 175, 196-204. [CrossRef]

(C) 2020 by the authors. Licensee MDPI, Basel, Switzerland. This article is an open access article distributed under the terms and conditions of the Creative Commons Attribution (CC BY) license (http://creativecommons.org/licenses/by/4.0/). 